\title{
Instrument for assessing mobile technology acceptability in diabetes self-management: a validation and reliability study
}

This article was published in the following Dove Press journal:

Patient Preference and Adherence

14 February 2017

Number of times this article has been viewed

\author{
Mirela Frandes' \\ Anca V Deiac ${ }^{2}$ \\ Bogdan Timar ${ }^{1,3}$ \\ Diana Lungeanu ${ }^{1,2}$ \\ 'Department of Functional \\ Sciences, "Victor Babes" University \\ of Medicine and Pharmacy of \\ Timisoara, ${ }^{2}$ Department of \\ Mathematics, Polytechnic University \\ of Timisoara, ${ }^{3}$ Third Medical Clinic, \\ Emergency Hospital of Timisoara, \\ Timisoara, Romania
}

Background: Nowadays, mobile technologies are part of everyday life, but the lack of instruments to assess their acceptability for the management of chronic diseases makes their actual adoption for this purpose slow.

Objective: The objective of this study was to develop a survey instrument for assessing patients' attitude toward and intention to use mobile technology for diabetes mellitus (DM) self-management, as well as to identify sociodemographic characteristics and quality of life factors that affect them. Methods: We first conducted the documentation and instrument design phases, which were subsequently followed by the pilot study and instrument validation. Afterward, the instrument was administered 103 patients (median age: 37 years; range: 18-65 years) diagnosed with type 1 or type $2 \mathrm{DM}$, who accepted to participate in the study. The reliability and construct validity were assessed by computing Cronbach's alpha and using factor analysis, respectively.

Results: The instrument included statements about the actual use of electronic devices for DM management, interaction between patient and physician, attitude toward using mobile technology, and quality of life evaluation. Cronbach's alpha was 0.9 for attitude toward using mobile technology and 0.97 for attitude toward using mobile device applications for DM selfmanagement. Younger patients (Spearman's $\rho=-0.429 ; P<0.001$ ) with better glycemic control (Spearman's $\rho=-0.322 ; P<0.001$ ) and higher education level (Kendall's $\tau=0.51 ; P<0.001$ ) had significantly more favorable attitude toward using mobile assistive applications for DM control. Moreover, patients with a higher quality of life presented a significantly more positive attitude toward using modern technology (Spearman's $\rho=0.466 ; P<0.001$ ).

Conclusion: The instrument showed good reliability and internal consistency, making it suitable for measuring the acceptability of mobile technology for DM self-management. Additionally, we found that even if most of the patients showed positive attitude toward mobile applications, only a moderate level of intention to indeed use them was observed. Moreover, the study indicated that barriers were truthfulness and easiness to use.

Keywords: mobile technology, mobile health, mHealth, Internet, disease management, diabetes, quality of life

\section{Introduction}

Mobile technology has become increasingly affordable and important in society, with new emerging concepts, such as mHealth. Although, mobile applications belong to our everyday life, embracing these gadgets in managing chronic conditions, such as diabetes and heart disease, is still slow. ${ }^{1}$

Diabetes mellitus (DM) is one of the most common widespread chronic diseases. Like other chronic diseases, DM has a major impact on both patient's health status and 
quality of life. The patient's quality of life may be decreased both in a direct and in an indirect manner: diagnosis of the disease has an immediate impact on patient's lifestyle; for DM management, the diagnosed patient has to improve his/ her diet-related habits and has to adopt a special schedule for taking the specific medication. On the other hand, the possible associated acute and chronic DM complications lead in a direct manner to an impairment in the patient's perception toward the quality of life. Acceptance of mobile technology among patients with DM may lead to a better selfmanagement and a better support from health care providers. ${ }^{2}$ Disease management among patients with DM is not just a matter of choice but also a social problem. Moreover, successful self-management demands knowledge and understanding of disease effects on the body, the goals of the treatment, and the consequences of various actions on glucose regulation. ${ }^{3,4}$ Hence, responsible behaviors, such as the capacity to learn, reason, and solve problems, result in better health behavior and overall self-management. ${ }^{5,6}$ Consequently, the continuous process of DM self-management is influenced not only by the socioeconomic factors but also by the cognitive skills. ${ }^{7}$

Many mHealth solutions for DM assistive control were proposed, ranging from technical interventions, ${ }^{8}$ web-based applications, ${ }^{9}$ clinical decision support systems, ${ }^{10}$ online self-management programs, ${ }^{11}$ and specific-task mobile applications ${ }^{12-15}$ to applications promoting behavior change techniques, but the actual use has been demonstrated to be still limited. ${ }^{16-19}$ However, the acceptance and use of mobile technology for disease management requires positive attitude and openness. ${ }^{20,21}$

Various survey-based instruments were developed and validated for DM care research, ranging from evaluation of patient satisfaction about disease management ${ }^{22}$ to instruments measuring self-care, ${ }^{23}$ disease knowledge ${ }^{24}$ or DM self-management barriers. ${ }^{25}$

The aim of this study was twofold, namely, 1) to develop an instrument that evaluates the attitude and behavior toward mobile technology for DM self-management and 2) to investigate if sociodemographic characteristics and health-related quality of life factors are drivers or barriers in accepting innovative technologies for DM management. Additionally, the study focused on real-time notifications and risk assessment that are expected from mobile applications and how the interaction between a physician and patient might change.

\section{Methods}

\section{Study design and participants}

In using mobile technology for better disease management, successful solutions for changing behavior proved to be those involving not only smart software engineering but also psychology theories and techniques. ${ }^{26}$ Therefore, we decided to design an assessment questionnaire from scratch, using the theory of planned behavior (TPB), designed to explain and predict human behavior in specific contexts. ${ }^{27}$

We followed sequential developing stages, namely, literature review and qualitative research and semi-structured interviews with physicians and diabetic patients. Afterward, we conducted a pilot study, which was subsequently followed by the development of the final version of the instrument. An overview of the study flow is illustrated in Figure 1.

Participants were aged between 18 and 65 years and had hemoglobin A1c (HbA1c) measured within the last 6 months. We excluded from the study patients who were not meeting the inclusion criteria or refused to participate in the study. The participants were recruited from the Emergency Hospital of Timisoara and the Diabetics Association of Timisoara, Romania. The enrollment held from April to December 2014, while the pilot study was conducted and validated in 2015. At the Emergency Hospital of Timisoara, the instrument was applied by a diabetic resident physician, while at the Diabetics Association of Timisoara, it was self-administered by diabetic patients. The study protocol and informed consent were reviewed and approved by the ethics committee of the Emergency Hospital of Timisoara. Each patient signed an informed consent.

\section{Pilot study}

The pilot version of the instrument included statements about the actual use of electronic devices, the attitude toward mobile technology, the disease management decisions, the confidentiality issues, and the evaluation of health-related quality of life and lifestyle. The instrument design followed the TPB, ${ }^{27}$ in conjunction with technology acceptance-related models. ${ }^{28,29}$ We considered that perceived usefulness influences both confidence and attitude toward using mobile technology. In addition, external factors were demographic and socioeconomic characteristics, quality of life level, as well as the actual use of electronic devices for DM self-management and the interaction between the patient and physician. A schematic representation of the used model is presented in Figure 2.

The rewording suggestions were integrated into the instrument's statements. The aim of the pilot data analysis was to develop and validate an investigation and a data collection instrument, an instrument that can be used and applied on a larger number of respondents in the next study phase.

\section{Internal consistency}

Internal consistency evaluates the strength of statements within their measured domains. Cronbach's alpha was used to evaluate 


\section{Phase 1. Documentation}

- Contextualization and definition of investigation problem

- Review of existing literature and similar studies

- Expert and target group opinion

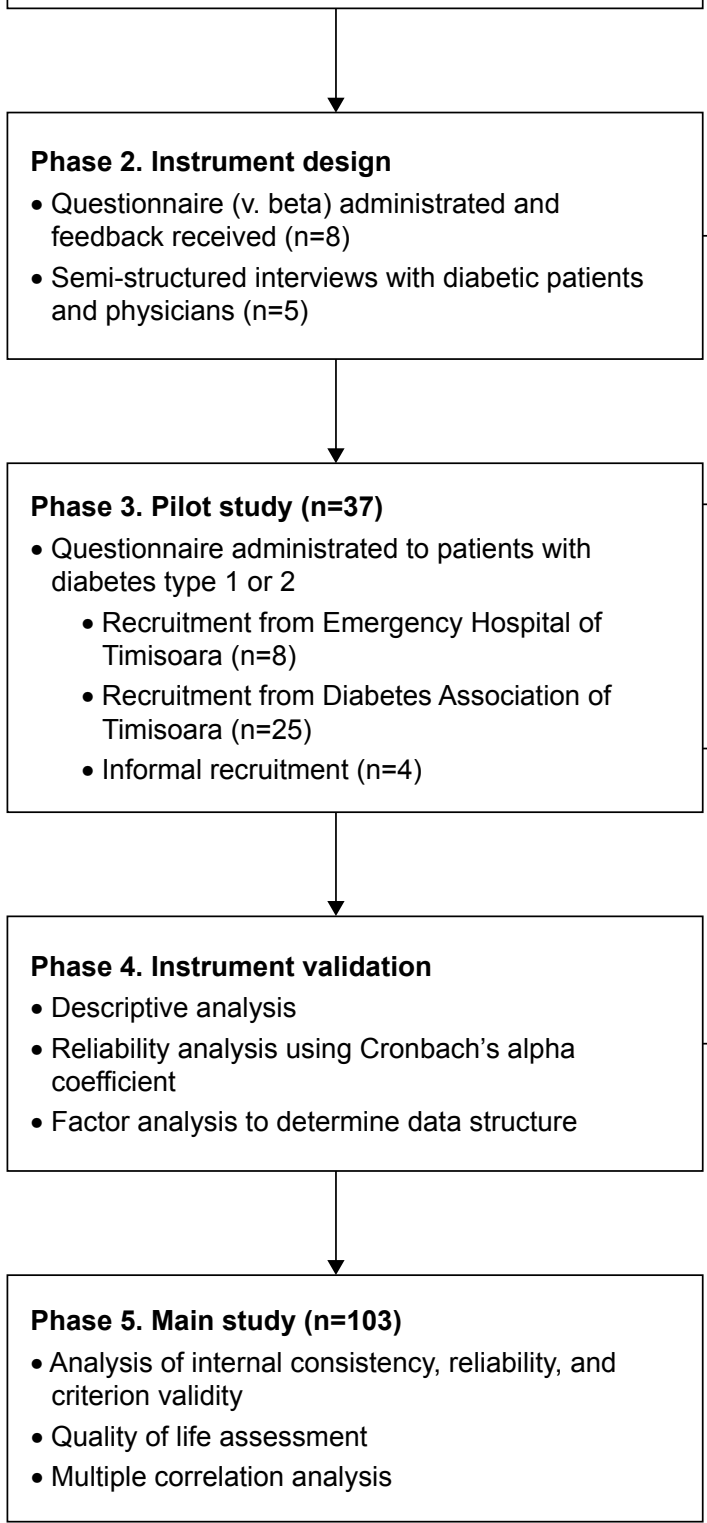

Phase 2. Instrument design

Questionnaire (v. beta) administrated and edback received $(n=8)$

Semi-structured interviews with diabetic patients
Phase 3. Pilot study ( $n=37$ )

Questionnaire administrated to patients with Timisoara $(n=8)$

Recruitment from Diabetes Association of

- Informal recruitment $(n=4)$
Figure I Summary of the study design.

Abbreviation: $\mathrm{HbAlc}$, hemoglobin Alc.

the internal reliability of all the sections of the pilot and final survey instrument. An acceptable coefficient is $\geq 0.7 .^{30}$

\section{Criterion and face validity}

The criterion validity ensures that a measurement instrument evaluates what it is meant to assess. ${ }^{31}$ It was achieved by administrating the questionnaire to two independent groups of participants who were expected to have different attitude toward and intention to use mobile technology.
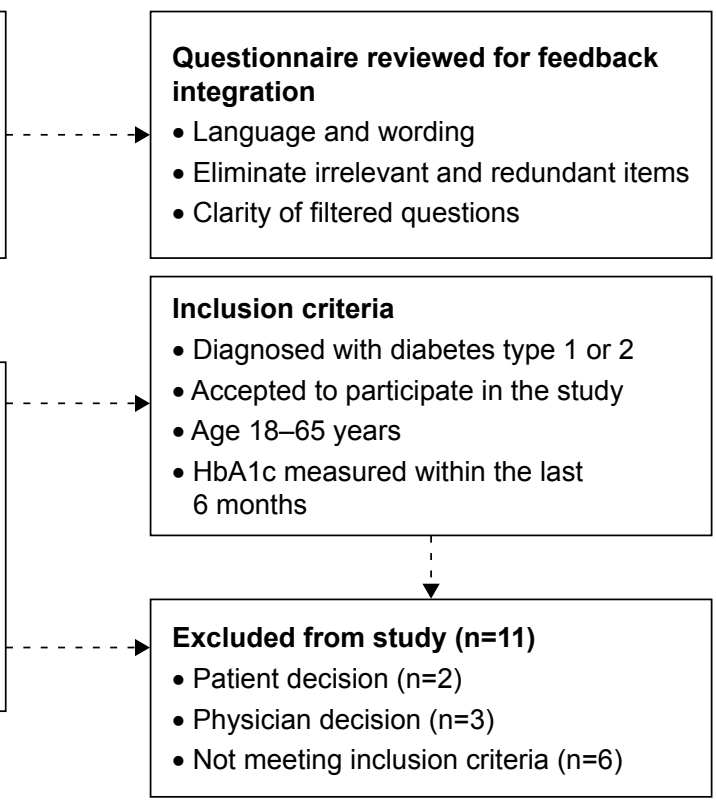

Data reduction - factor analysis

- Principal components method with Varimax rotation

- Extraction communality $>0.35$

- Excluded factor loadings with eigenvalue $<1$
Face validity ensures the appropriateness and ease to complete the questions. ${ }^{32}$ It was guaranteed by professionals' and patients' review during the pilot study.

\section{Content validity}

Content validity was assessed by analyzing if the semantic is compatible with the study population and if the presentation of attributes is adequate. In addition, semi-structured interviews with diabetic patients and physicians were conducted, 


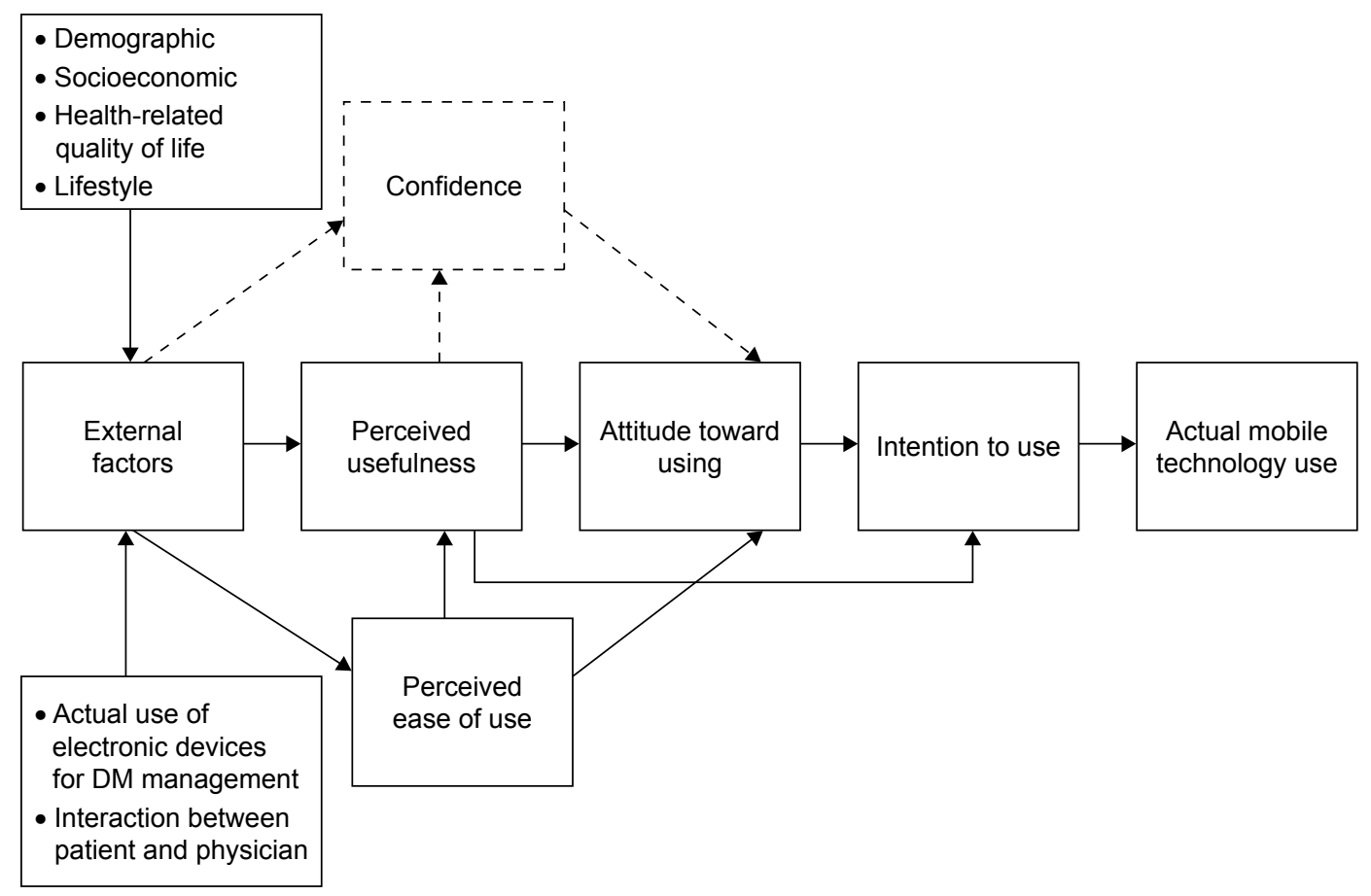

Figure 2 Mobile technology acceptance model for DM self-management. Abbreviation: DM, diabetes mellitus.

and the received feedback was integrated into a revised version of the instrument during the pilot study.

\section{Construct validity}

Construct validation was assured by performing exploratory factor analysis with principal component analysis and orthogonal rotation via the Varimax method. The principal component analysis was used to extract the factors with eigenvalues $>1.0$ and factor loading $>5.0$. Initial sampling adequacy was evaluated by using the Kaiser-Meyer-Olkin (KMO) test and the Bartlett's test of sphericity.

\section{Main study}

The final version of the instrument included five main sections, which measured 1) actual use of electronic devices for DM self-management; 2) interaction between patient and physician, and attitude toward mobile technology and mobile device applications for DM self-management, which was indirectly measured by 3 ) perceived ease of use; 4) perceived usefulness; and 5) confidence. The actual use of electronic monitoring was assessed by five statements designed on 5-point Likert scale, 1 indicating complete disagreement and 5 indicating complete agreement. The perceived ease of use and confidence about mobile technology were assessed by four statements each, also designed on 5-point Likert scale, 1 indicating complete disagreement and 5 indicating complete agreement. The perceived usefulness of mobile device applications for DM management was assessed by statements designed on 10-point Stapel scale, 1 corresponding to not at all useful and 10 corresponding to very useful.

\section{Health-related quality of life and lifestyle}

Health-related quality of life was evaluated by three main aspects, considering 1) the degree of satisfaction about usual activities of a diabetic patient, such as the time spent to measure the glycemic level and the time spent to make physical activities; 2) how often DM negatively influences patients' life; and 3) how often (in the last 3 months) the DM-related events caused problems when doing usual physical activities.

For assessing the first aspect, we included seven statements on 5-point Likert scale, 1 corresponding to very unsatisfied and 5 corresponding to very satisfied, while the other two aspects were each one evaluated by six statements designed on 5-point Likert scale, 1 indicating very often and 5 indicating very rare. For each patient, we quantified a total score, which was considered a measure of the patients' health-related quality of life.

Lifestyle was assessed by open-answer and multiplechoice questions about the frequent physical activities, the usual method of transport, or the number of days with at least 30 minutes of physical activity of moderate or high 
intensity, such as actively walking, riding bicycle, swimming, and jogging.

\section{Statistical analysis}

For categorical variables, description was done by their absolute frequencies or percent and for continuous variables with non-Gaussian distribution by median and interquartile range (IQR). The applied statistical tests were Mann-Whitney $U$ test for investigation of differences between central tendency in case of rang variables and Kruskal-Wallis test for comparing median ranks for more than two groups. To assess the existence of correlation between patient's age, quality of life, optimal glycemic control, and attitude toward and intention to use modern technologies and mobile device applications for assistance in DM self-management, we computed the Spearman's $\rho$ correlation coefficient, while Kendall's $\tau$ was derived to investigate the existence of correlation between education level, working status, income, and attitude toward and intention to use mobile technologies.

The degree of positive attitude toward and intention to use mobile technology and mobile device applications was calculated as the weighted mean of the corresponding points and the number of respondents, for statements designed on 5-point Likert and 10-point Stapel scales. The obtained coefficient ranged between 0 as the lower limit, corresponding to a total negative attitude and intention, and 1 as the upper limit, corresponding to a total positive attitude and intention. For multiple-choice questions, attitude was expressed as proportions of patients who had chosen the respective options.

A limit of 0.05 was considered the statistical significance threshold. Statistical processing was performed with SPSS v17 (SPSS Inc., Chicago, IL, USA).

\section{Results}

\section{Participants}

Demographic, socioeconomic, and anthropometric characteristics of the participants are presented in Table 1. The median age of the participants was 37 years (IQR: 26-59 years), and female participants were in proportion of $50.5 \%$. Most of the participants were patients diagnosed with type $1 \mathrm{DM}(61.2 \%)$, while only a low proportion of patients had an optimal DM management $(\mathrm{HbA} 1 \mathrm{c}<7.5 \%)$ in the last 6 months $(35.9 \%)$. More than a half of the patients $(52.4 \%)$ were diagnosed with DM for $>10$ years. Most of the patients (64.0\%) had high school or bachelor as their highest education level, while $9.8 \%$ did not have an education. The highest proportion of patients $(52.2 \%)$ were unemployed or independent, while
Table I Patients' anthropometric, demographic, and socioeconomic characteristics

\begin{tabular}{|c|c|}
\hline Patients' characteristics & Values \\
\hline Number of patients & 103 \\
\hline \multicolumn{2}{|l|}{$\mathrm{DM}^{\mathrm{a}}$} \\
\hline Type I & $63(61.16)$ \\
\hline Type 2 & $40(38.83)$ \\
\hline Age (years) ${ }^{b}$ & $37(26-59)$ \\
\hline Gender (female) ${ }^{\mathrm{a}}$ & $52(50.5)$ \\
\hline Weight $(\mathrm{kg})^{\mathrm{b}}$ & $73(63.5-89.5)$ \\
\hline Height $(\mathrm{cm})^{\mathrm{b}}$ & $167.5(163-173.5)$ \\
\hline Abdominal circumference $(\mathrm{cm})^{\mathrm{b}}$ & $80(69.5-101)$ \\
\hline \multicolumn{2}{|l|}{ DM duration ${ }^{\mathrm{a}}$} \\
\hline$<$ I year & $10(9.7)$ \\
\hline $\mathrm{I}-5$ years & $15(14.6)$ \\
\hline $6-10$ years & $24(23.3)$ \\
\hline$>10$ years & $54(52.4)$ \\
\hline Latest $\mathrm{HbAlc}<7.5^{\mathrm{a}}$ & $37(35.9)$ \\
\hline Major cardiovascular events (yes) & $9(8.7)$ \\
\hline \multicolumn{2}{|l|}{ Education level $^{\mathrm{a}}$} \\
\hline Without studies & $10(9.8)$ \\
\hline Elementary level & $2(4.9)$ \\
\hline Secondary level & $9(8.7)$ \\
\hline Professional school & $13(12.6)$ \\
\hline High school & $33(32)$ \\
\hline Bachelor & $33(32)$ \\
\hline Master/PhD & $3(2.9)$ \\
\hline \multicolumn{2}{|l|}{ Employment status $^{\mathrm{a}}$} \\
\hline Unemployed & $13(12.6)$ \\
\hline Retired & $36(35)$ \\
\hline Working full time & $29(28.2)$ \\
\hline Working part time & I (0.97) \\
\hline Independent & $13(12.6)$ \\
\hline \multicolumn{2}{|l|}{ Total income $\mathrm{a}^{\mathrm{a}}$} \\
\hline Low level & $31(30.1)$ \\
\hline Middle level & $44(38.9)$ \\
\hline High level & $8(7.8)$ \\
\hline I do not want to answer/l do not know & $24(23.3)$ \\
\hline
\end{tabular}

Notes: a Categorical variables are presented by absolute frequency and percentage in the sample. ${ }^{\text {bC }}$ Continuous variables (with non-Gaussian distribution) are indicated by their median (interquartile range).

Abbreviations: DM, diabetes mellitus; HbAlc, hemoglobin Alc.

a proportion of $35.0 \%$ were retired and only $28.2 \%$ were full-time workers. A total of $38.9 \%$ and $30.1 \%$ of patients had middle- and low-income levels, respectively, while only $7.8 \%$ had a high-income level and $23.3 \%$ did not know or did not want to answer.

Participants indicated that they used classical auxiliary instruments for various activities related to DM management, namely, noting glycemic values (63.1\%), eaten food types $(24.3 \%)$, physical activities $(14.6 \%)$, and tracking administered medication (32.0\%). Most of the patients used glucometer (90.3\%) and blood pressure monitor (33.0\%). For disease management, most of the patients, $80.6 \%$ and $66.0 \%$, declared that the decisions were taken by the physician and themselves, respectively, while only a small proportion 
(15.5\%) said that their family participates in taking decisions about their disease.

A large proportion of patients had Internet access (75.7\%). Almost half of them used a PC (46.6\%) and fewer used a mobile phone (44.7\%), a laptop (39.8\%), or a tablet $(11.7 \%)$. More than a half of the patients used Internet several times a day (57.3\%), while only $6.8 \%$ had Internet access only once in a day. Most of the patients indicated that they usually use Internet for social networks (58.3\%), e-mails (48.5\%), news or weather forecast (40.8\%), documentation $(35.0 \%)$, forums dedicated to patients $(31.1 \%)$, games and entertainment (29.1\%), and online shopping (21.4\%).

We found that most of the patients (94.1\%) owned a mobile phone and only a half $(51.0 \%)$ had a smartphone, while $10.4 \%$ of the patients did not know the type of their mobile phone.

\section{Pilot study}

The first version of the survey instrument was analyzed question by question. We chose to present the analysis for one statement, but we went through all statistical procedures for the entire instrument. For example, the actual use of electronic devices for DM self-management was evaluated by five items. Each item was separately rated on a 5-point Likert scale, where 1 represented a strongly disagree and 5 denoted a strongly agree. We calculated Cronbach's alpha coefficient on all five items, obtaining a value below the recommended limit of 0.7 for internal consistency, which suggested an internal design issue for the statement. For improving the score, a solution was to eliminate the items. In addition, factor analysis with principal component method was applied. Two factors were extracted with eigenvalues $>1$, explaining $57.3 \%$ of total items variance. For a better interpretation of factor loadings, the initial extraction solution was rotated using the Varimax method and only those with communalities $>0.35$ were accepted.

The results obtained through rotated solution confirm the reliability analysis made on the statement. Items were factored in a separate component, confirming that they belonged to a different dimension than the one investigated. Rerunning the principal component analysis with only four items included led to an improved KMO and a new Cronbach's alpha coefficient of 0.85 .

\section{Construct validity}

Considering the results of the pilot study, we designed the final version of the survey instrument. The KMO measure of the sampling adequacy was 0.877 , while the Bartlett's test of sphericity showed a significant relationship among instrument's statements $\left(\chi^{2}(496)=3,746.8 ; P<0.001\right)$. Table 2 presents the loadings of the statements belonging to the five extracted components, after Varimax rotation with Kaiser normalization. Coefficients with an absolute value $<0.5$ were not considered. Components depicting the perceived usefulness loaded on the first factor explained $45.5 \%$ of the variance on the sample, while components about the actual use of electronic devices for DM management loaded on a second factor explained $13.8 \%$ of the variance. In addition, components about the perceived ease of use loaded on a third factor explained $10.1 \%$ of the variance, while the components about confidence and patientphysician interaction loaded on factors four and five explained $4.6 \%$ and $4.4 \%$ of the variance, respectively.

\section{Internal consistency}

Computing Cronbach's alpha, we found a very good internal consistency for the attitude toward mobile technology for DM self-management and the compound parts, namely, perceived ease of use of mobile technology for DM self-management, confidence about technology and latest generation products, and perceived usefulness of notifications about the risk of DM-related complications. Alpha values were $>0.7$ for all the components measuring the attitude toward mobile technology for DM self-management (Table 3).

Cronbach's alpha indicated a good internal reliability for both the attitude toward mobile device applications for DM self-management and the compound parts, namely, tracking functions of glycemic values, ingested carbohydrates, administered medication, security and confidentiality of personal data, backup system, data portability, multiple user profiles, off-line notifications, and notifications about medication administration, eating behaviors, and physical effort optimization. Alpha values were $>0.7$ for all the components measuring the attitude toward mobile applications for DM self-management (Table 4).

\section{Criterion validity}

Total scores for the section measuring the attitude toward using mobile technology for DM control of the group using Internet and the group not using Internet were compared. Scores differed statistically significantly between groups for the respective section (Mann-Whitney $U$ test, $U=486$; $P<0.001)$. At the same time, total scores for the section measuring the attitude toward various attributes of a mobile device application for DM self-management of the group using smartphone and the group not using smartphone were compared. Similarly, scores differed statistically significant between groups for the respective section (Mann-Whitney $U$ test, $U=360 ; P<0.001)$. 
Table 2 Results of factor analysis - rotated component matrix

\begin{tabular}{|c|c|c|c|c|c|}
\hline \multirow[t]{2}{*}{ Instrument's statements } & \multicolumn{5}{|c|}{ Component } \\
\hline & $\mathbf{I}$ & 2 & 3 & 4 & 5 \\
\hline Electronic monitoring is more precise & 0.278 & 0.842 & 0.054 & $0.06 \mathrm{I}$ & 0.041 \\
\hline Electronic monitoring is more convenient & 0.153 & 0.863 & 0.047 & -0.125 & -0.062 \\
\hline Raises confidence in decisions for DM monitoring & 0.104 & 0.759 & 0.294 & 0.157 & 0.056 \\
\hline Helps monitor the hyper- or hypoglycemic events & -0.001 & 0.818 & 0.188 & 0.01 & -0.294 \\
\hline New technology is helpful & 0.216 & -0.039 & -0.114 & -0.598 & 0.413 \\
\hline I am actively interested in testing cutting-edge products & 0.199 & 0.095 & 0.754 & -0.202 & -0.148 \\
\hline I want to learn myself how to use cutting-edge products & 0.276 & 0.227 & 0.815 & 0.255 & 0.045 \\
\hline I am passionate about exploring the potential of cutting-edge products & 0.271 & 0.258 & 0.803 & 0.308 & 0.073 \\
\hline Technology is part of my life & 0.479 & 0.339 & 0.386 & 0.574 & 0.076 \\
\hline Utility of a smartphone application & 0.708 & -0.119 & 0.186 & -0.025 & 0.169 \\
\hline Utility of notifications & 0.799 & -0.065 & 0.131 & 0.063 & 0.001 \\
\hline Tracking glycemic values & 0.837 & -0.022 & 0.353 & -0.127 & -0.063 \\
\hline Tracking ingested carbohydrates & $0.84 I$ & 0.146 & 0.288 & -0.024 & -0.028 \\
\hline Tracking daily physical activity & $0.86 \mathrm{I}$ & 0.154 & 0.110 & 0.200 & 0.027 \\
\hline Tracking administered medication & 0.766 & 0.245 & 0.365 & -0.168 & 0.149 \\
\hline Monitoring by the physician and medication adjustment & 0.732 & -0.22 & 0.168 & -0.295 & -0.243 \\
\hline Security and confidentiality of the personal data & 0.784 & 0.281 & 0.163 & -0.200 & -0.192 \\
\hline Multiple user profiles & 0.792 & 0.297 & 0.119 & -0.036 & -0.158 \\
\hline Option to input data on a website & 0.836 & 0.423 & 0.042 & -0.088 & -0.102 \\
\hline Backup system for information already included & 0.865 & 0.298 & -0.092 & 0.221 & -0.144 \\
\hline Sending data; export and print the inputted information & 0.890 & 0.304 & -0.068 & 0.185 & -0.097 \\
\hline Notification without Internet connection & 0.845 & 0.290 & -0.007 & 0.270 & -0.115 \\
\hline Available on many operating systems & 0.847 & 0.397 & 0.119 & -0.065 & -0.127 \\
\hline Available on many languages & 0.826 & 0.217 & 0.335 & -0.087 & -0.064 \\
\hline Notifications about medication administration & 0.807 & 0.163 & 0.258 & -0.202 & 0.078 \\
\hline Notifications about eating behavior & 0.855 & 0.196 & 0.274 & -0.123 & 0.047 \\
\hline Notifications about physical effort optimization & 0.921 & 0.130 & 0.071 & 0.145 & -0.014 \\
\hline Alerts a potential risk & 0.839 & 0.082 & 0.152 & 0.241 & 0.057 \\
\hline Interaction with the physician & -0.168 & -0.077 & 0.002 & -0.097 & 0.844 \\
\hline
\end{tabular}

Note: The bold values show the statements which loaded in each of the five components.

Abbreviation: DM, diabetes mellitus.

\section{Health-related quality of life and lifestyle}

We found a moderate level of patients' satisfaction about their current treatment of DM (0.676) and the time spent for DM-related activities (0.61). Additionally, we observed moderate frequencies, when looking how often DM negatively influences the social life of the patients and their overall well-being. In addition, almost a half of patients $(49.15 \%)$ declared that they were not satisfied about their weight.

\section{Attitude toward and intention to use mobile technology}

A rather moderate rate $(0.682)$ of positive attitude toward using innovative technologies for DM control and a moderate

Table 3 Attitude toward mobile technology for DM self-management

\begin{tabular}{|c|c|c|c|c|c|}
\hline \multirow[t]{2}{*}{ Components } & \multirow{2}{*}{$\begin{array}{l}\text { Internal } \\
\text { consistency } \\
\alpha^{a}\end{array}$} & \multirow{2}{*}{$\begin{array}{l}\text { Reliability } \\
\text { ICC }\end{array}$} & \multicolumn{3}{|c|}{ Criterion validity } \\
\hline & & & Group & Median (IQR) ${ }^{b}$ & $P$-value \\
\hline (I) Perceived ease of use of mobile technology & 0.898 & 0.746 & Group I & $11.5(9-14)$ & $<0.001$ \\
\hline for DM self-management & & & Group 2 & $5(I-10)$ & \\
\hline (II) Confidence about technology and latest & 0.909 & 0.714 & Group I & $15(12.5-18.5)$ & $<0.001$ \\
\hline generation products & & & Group 2 & $5(2.5-20)$ & \\
\hline (III) Usefulness of notifications about the risk & 0.9 & 0.818 & Group I & $19(15-20)$ & $<0.01$ \\
\hline of DM-related complications & & & Group 2 & $10(4-20)$ & \\
\hline
\end{tabular}

Notes: a Cronbach's alpha. 'Attitude rated where the lower limit indicates poor attitude and the upper limit indicates good attitude (I) I-25, (II) I-20, and (III) I-20. cMann-Whitney $U$ test, null hypothesis: the distribution of scores is the same across the categories of using or not Internet.

Abbreviations: DM, diabetes mellitus; ICC, interclass correlation coefficient; IQR, interquartile range; Group I, group of patients using Internet; Group 2, group of patients not using Internet. 
Table 4 Perceived usefulness about the inclusion of various attributes into a mobile device application for DM self-management

\begin{tabular}{|c|c|c|c|c|c|}
\hline \multirow{2}{*}{$\begin{array}{l}\text { Attributes of mobile device applications for DM } \\
\text { self-management }\end{array}$} & \multirow{2}{*}{$\begin{array}{l}\text { Internal } \\
\text { consistency } \\
\alpha^{a}\end{array}$} & \multirow{2}{*}{$\begin{array}{l}\text { Reliability } \\
\text { ICC }\end{array}$} & \multicolumn{3}{|c|}{ Criterion validity } \\
\hline & & & Group & Median (IQR) ${ }^{b}$ & $P$-value \\
\hline (I) Tracking functions for glycemic values, ingested & 0.949 & 0.823 & Group I & $40(36-40)$ & $<0.001$ \\
\hline carbohydrates, and administered medication & & & Group 2 & $28(9-36)$ & \\
\hline (II) Security and confidentiality of personal data, backup & 0.978 & 0.815 & Group I & $99(85.5-100)$ & $<0.001$ \\
\hline system, data portability, and off-line notifications & & & Group 2 & $57(20-85)$ & \\
\hline (III) Notifications about medication administration, & 0.97 & 0.889 & Group I & $40(34-40)$ & $<0.001$ \\
\hline eating behaviors, and physical effort optimization & & & Group 2 & $25.5(8-37.5)$ & \\
\hline
\end{tabular}

Notes: ${ }^{a}$ Cronbach's alpha. ${ }^{\text {A} A t t i t u d e ~ r a t e d ~ w h e r e ~ t h e ~ l o w e r ~ l i m i t ~ i n d i c a t e s ~ p o o r ~ a t t i t u d e ~ a n d ~ t h e ~ u p p e r ~ l i m i t ~ i n d i c a t e s ~ g o o d ~ a t t i t u d e ~(I) ~ I-40 ; ~(I I) ~ I-I 00 ; ~(I I I) ~ I-40 . ~ ' M a n n-~}$ Whitney $U$ test, null hypothesis: the distribution of scores is the same across the categories of using or not using smartphone.

Abbreviations: DM, diabetes mellitus; ICC, interclass correlation coefficient; IQR, interquartile range; Group I, group of patients using smartphone; Group 2, group of patients not using smartphone.

level (0.63) of confidence that these technologies could indeed be helpful for DM self-management were measured. In addition, we found that $28.2 \%$ of the patients liked to be among the first ones who use cutting-edge products. Similar proportions, $30.1 \%$ and $27.2 \%$, used mobile technology to stay in touch with other people or to stay in contact with the family, while $10.7 \%$ of patients could live without a mobile phone.

On the contrary, a high rate $(0.832)$ of perceived usefulness of modern technologies and a high rate of intention (0.811) to use these technologies for receiving advice and notifications about the risk to develop certain complications associated with DM were observed.

\section{Attitude toward and intention to use mobile device applications}

We observed a high rate of positive attitude (0.852) toward mobile device applications for DM control. In addition, high rates of positive attitude were observed when considering the inclusion of different attributes, such as security and confidentiality of personal data (0.831); backup system for information already included (0.751); send, export, and print data (0.75); multiple user profiles (0.788); notifications about Internet connection ( 0.763$)$; availability on many operating systems (0.767); and availability on many languages (0.836). Similarly, we observed a high rate of positive attitude toward and intention to use mobile application if it would be free.

Considering application's functions of tracking glycemic values, ingested carbohydrates, daily physical activity, and administered medication, we found a high level of perceived usefulness (0.814) about their inclusion into a mobile application. Similarly, we observed high levels of confidence about the inclusion of notifications for medication administration (0.815), eating behaviors ( 0.811$)$, physical activities optimization (0.788), and alerts of potential DM-related risks (0.849). When asking about what information would be more useful to include into an assistive mobile application, most of the patients said glycemic values (71.8\%) and medication administration with daily doses $(43.7 \%)$ and less answered information about ingested carbohydrates (32.0\%), weight (33.0\%), laboratory results (34.0\%), and daily physical activity (27.2\%). A statement about the intention to use mobile applications was formulated negatively instead of positively to force patients to evaluate every statement on its own. We found that almost a half of the patients would not use applications if the information already inserted would be lost (48.5\%), the price would be high (40.8\%), in case of not receiving notifications (36.9\%), and in case it would be in a foreign language (35.9\%). Moderate proportions of patients answered that reasons for not using mobile applications would be having to learn by themselves how to use the application (21.4\%), having to insert too much information in the application (22.3\%) and lack of experience using mobile technologies (17.5\%).

We observed a very low confidence about using mobile device applications for taking decisions about the disease (4.9\%), when comparing to physician advice, but a higher proportion of patients (21.4\%) would use both applications and their physician, when comparing to physicians alone, themselves, or their family. In addition, $43.5 \%$ considered that using applications would change the interaction with their physician. A high percent of patients (63.1\%) would agree to give their DM-related data for developing an application. Finally, we observed only a moderate level of intention (0.671) to actually use mobile applications for assistance in DM control. To further underline the results, we tested the structural acceptance model, as described in Figure 2. The actual use of electronic devices for DM self-management was found to have a significant influence on perceived usefulness. Additionally, we observed that the perceived ease of use and perceived usefulness had a strong impact on trust and intention to use (Figure 3). This highlights the importance of usability and usefulness for mobile technology and mobile device applications. 


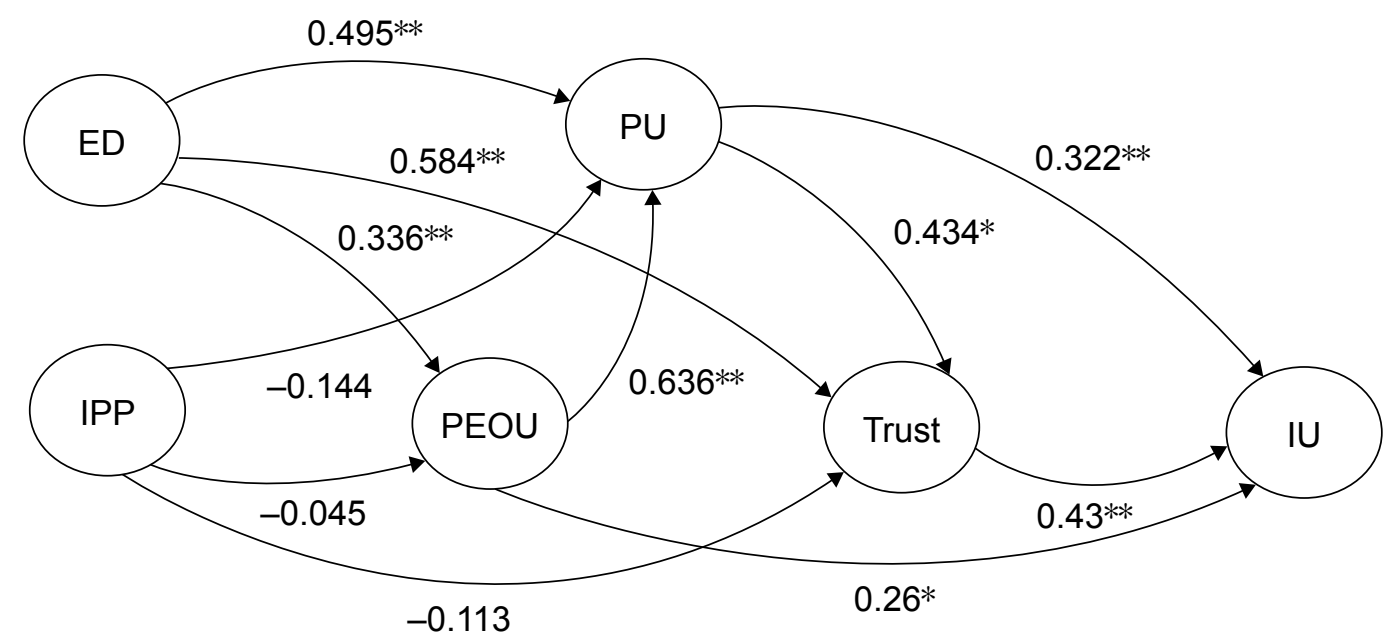

Figure 3 The correlated factors of the mobile technology acceptance model for DM self-management.

Notes: *Correlation is significant at the 0.05 level (two tailed $t$-test); **Correlation is significant at the 0.01 level (two tailed $t$-test).

Abbreviations: DM, diabetes mellitus; IPP, interaction patient-physician; ED, electronic devices; PEOU, perceived ease of use; PU, perceived usefulness; IU, intention to use.

A multiple correlation analysis evaluated the association between both sociodemographic characteristics and quality of life factors and attitude toward using mobile technology and mobile device applications for DM self-management. We found that younger patients had a significantly more positive attitude toward using mobile technology (Spearman's $\rho=-0.393 ; P<0.001)$ and mobile device applications (Spearman's $\rho=-0.429 ; P<0.001$ ). In addition, patients with a higher quality of life presented a significantly more favorable attitude toward mobile technology (Spearman's $\rho=0.37$; $P<0.001$ ) and mobile device applications (Spearman's $\rho=0.466 ; P<0.001$ ). Moreover, patients with optimal glycemic control had more positive attitude toward both mobile technology for DM self-management (Spearman's $\rho=-0.322$; $P<0.001$ ) and mobile applications (Spearman's $\rho=-0.317$; $P<0.001)$. A higher education level significantly correlated with more favorable attitude toward mobile applications (Kendall's $\tau=0.33 ; P<0.001$ ). Similarly, participants who had higher income presented a significantly more favorable attitude toward mobile applications (Kendall's $\tau=0.33$; $P=0.002$ ). Gender had no significant impact on the attitude toward mobile technology (Mann-Whitney test, $U=727.5$; $P=0.46$ ), neither the length of DM (Kruskal-Wallis test, $H(3)=3.331 ; P=0.343)$. On the contrary, superior employment status significantly associated with a more positive attitude toward mobile technology (Kruskal-Wallis test, $H(8)=28.62 ; P<0.001)$.

\section{Discussion}

Novelty of the study is brought by the proposed instrument to assess the attitude toward and intention to use modern technology and mobile device applications for
DM self-management, as well as its design and validation process. Assessment of the instrument's validation and reliability was done on a national sample, in conjunction with multiple correlation analysis, including demographic and socioeconomic characteristics, as well as health-related quality of life factors.

The instrument was self-administered or administered by a diabetic resident physician. On the site where the instrument was self-administered, the participants were younger and had a higher education level. On the contrary, on the site where the instrument was administered by a resident physician, the participants were older and had a lower education level. Moreover, each participant was trained about how to fill-in the questionnaire before completion. Therefore, the way the instrument was administered should not influence the answers.

For designing the survey instrument, we took advantage from the TPB and technology acceptance models, which clearly separate the attitude toward intention and actual adoption. We observed that the main components influencing the attitude toward mobile technology and mobile applications for DM self-management were the actual use of electronic devices for DM monitoring and perceived usefulness. In fact, the perceived usefulness has also been found as a principal factor increasing the acceptance of smartphones for health care professionals. ${ }^{33}$

We observed that younger patients presented a more positive attitude toward and intention to use mobile technology. The result might relay on the fact that young patients are generally more enthusiastic about the use of communication technologies. This fact may overcome the usual barriers to technology adoption, ${ }^{34}$ in comparison with older patients, for 
whom using mobile technology and mobile device applications is more challenging. ${ }^{35}$

Nevertheless, even for the young patients, there is a gap between wanting to use technology in self-management and actually using it. ${ }^{36}$ Considering the principles of the TPB, we could say that if behavioral intention is under volitional control, other factors may influence it, such as time, financial resources, and technological skills, which represent the actual control over the behavior. Indeed, we found that patients with a higher income, education level, and health-related quality of life had a more favorable attitude toward and intention to use mobile technology for assistive DM control.

\section{Conclusion}

New health care strategies should empower the users, the patients themselves, by engaging them in managing their own health. In this context, our study brings the instrument to assess the evidence of effectively beneficial changes mHealth and handheld devices would leverage in the management of chronic diseases.

\section{Acknowledgments}

The authors gratefully acknowledge the professionals from the Emergency Hospital of Timisoara and the Diabetics Association of Timisoara, Romania, for their support during the recruitment phase. At the same time, the authors kindly acknowledge their colleagues Otilia-Ana Porojan and Sergiu Gabriel Pop from the Polytechnic University of Timisoara, Romania, for the valuable contribution in the early stages of this work.

\section{Disclosure}

The authors report no conflicts of interest in this work.

\section{References}

1. Hamine S, Gerth-Guyette E, Faulx D, Green BB, Ginsburg AS. Impact of mHealth chronic disease management on treatment adherence and patient outcomes: a systematic review. J Med Internet Res. 2015;17(2):e52.

2. Dayer L, Heldenbrand S, Anderson P, Gubbins PO, Martin BC. Smartphone medication adherence apps, potential benefits to patients and providers. J Am Pharm Assoc. 2013;53(2):172-181.

3. Weijmana I, Ros WJG, Rutten GE, Schaufeli WB, Schabracq MJ, Winnubst JAM. The role of work-related and personal factors in diabetes self-management. Patient Educ Couns. 2005;59(1):87-96.

4. Brunisholz KD, Briot P, Hamilton S, et al. Diabetes self-management education improves quality of care and clinical outcomes determined by a diabetes bundle measure. J Multidiscip Healthc. 2014;7:533-542.

5. Bandura A. Health promotion by social cognitive means. Health Educ Behav. 2004;31(2):143-164.

6. Onwudiwe NC, Mullins CD, Winston RA, et al. Barriers to self-management of diabetes: a qualitative study among low-income minority diabetics. Ethn Dis. 2011;21(1):27-32.
7. Gottfredson LS, Deary IJ. Intelligence predicts health and longevity, but why? Curr Dir Psychol Sci. 2004;13:1-4.

8. Gaikwad R, Warren J. The role of home-based information and communications technical interventions in chronic disease management: a systematic review. Health Info J. 2009;15:122-145.

9. McMahon GT, Gomes HE, Hohne SH, Hu TM, Levine BA, Conlin PR. Web-based care management in patients with poorly controlled diabetes. Diabetes Care. 2005;28(7):1624-1629.

10. Frandes M, Timar B, Tole A, Holban S, Lungeanu D. Mobile technology support for clinical decision in diabetic keto-acidosis emergency. Stud Health Technol Inform. 2015;210:316-320.

11. Lorig K, Ritter PL, Laurent DD, et al. Online diabetes selfmanagement program: a randomized study. Diabetes Care. 2010; 33(6): 1275-1281.

12. Tran J, Tran R, White JR. Smartphone-based glucose monitors and applications in the management of diabetes: an overview of 10 salient "apps" and a novel smartphone-connected blood glucose monitor. Clin Diabetes. 2012;30(4):173-178.

13. Curran K, Nichols E, Xie E, Harper R. An intensive insulinotherapy mobile phone application built on artificial intelligence techniques. J Diabetes Sci Technol. 2010;4(1):209-220.

14. Donald H, Franklin V, Greene AH. The use of mobile phones in dietary assessment in young people with type 1 diabetes. J Hum Nutr Diet. 2009; 22(3):256-257.

15. Knight BA, McIntyre HD, Hickman IJ, Noud M. Qualitative assessment of user experiences of a novel smart phone application designed to support flexible intensive insulin therapy in type 1 diabetes. $B M C$ Med Inform Decis Mak. 2016;16:119.

16. Hoppe CD, Cade JE, Carter M. An evaluation of diabetes targeted apps for Android smartphone in relation to behaviour change techniques. J Hum Nutr Diet. Epub 2016 Oct 17:1-13.

17. Connelly J, Kirk A, Masthoff J, MacRury S. The use of technology to promote physical activity in type 2 diabetes management: a systematic review. Diabet Med. 2013;30(12):1420-1432.

18. Free C, Phillips G, Galli L, et al. The effectiveness of mobile-health technology-based health behaviour change or disease management interventions for health care consumers: a systematic review. PLoS Med. 2013;10(1):e1001362.

19. Bentley CL, Otesile O, Bacigalupo R, et al. Feasibility study of portable technology for weight loss and $\mathrm{HbA} 1 \mathrm{c}$ control in type 2 diabetes. $B M C$ Med Inform Decis Mak. 2016;16:92.

20. Kirwan M, Vandelanotte C, Fenning A, Duncan MJ. Diabetes selfmanagement smartphone application for adults with type 1 diabetes: randomized controlled trial. J Med Internet Res. 2013;15(11):e235.

21. Pinnock H, Slack R, Pagliari C, Price D, Sheikh A. Professional and patient attitudes to using mobile phone technology to monitor asthma: a questionnaire survey. Prim Care Respir J. 2006;15:237-245.

22. Paddock LE, Veloski J, Chatterton ML, Gevirtz FO, Nash DB. Development and validation of a questionnaire to evaluate patient satisfaction with diabetes disease management. Diabetes Care. 2000; 23(7):951-956.

23. Stetson B, Schlundt D, Rothschild C, Floyd JE, Rogers W, Mokshagundam SP. Development and validation of The Personal Diabetes Questionnaire (PDQ): a measure of diabetes self-care behaviors, perceptions and barriers. Diabetes Res Clin Pract. 2011;91(3): 321-332.

24. Eigenmann CA, Skinner T, Colagiuri R. Development and validation of a diabetes knowledge questionnaire. Prac Diabetes. 2011;28(4):166-170.

25. Cox ED, Fritz KA, Hansen KW, et al. Development and validation of PRISM: a survey tool to identify diabetes self-management barriers. Diabetes Res Clin Pract. 2014;104(1):126-135.

26. Vuong AM, Huber JC, Bolin JN, et al. Factors affecting acceptability and usability of technological approaches to diabetes self-management: a case study. Diabetes Technol Ther. 2012;14(12):1178-1182.

27. Ajzen I. The theory of planned behavior. Organ Behav Hum Decis Process. 1991;50:179-211. 
28. Davis FD. Perceived usefulness, perceived ease of use and user acceptance of information technology. MIS Q. 1989;13(3):319-340.

29. King WR, He J. A meta-analysis of the technology acceptance model. Inf Manage. 2006;43(6):740-755.

30. DeVellis R. Scale Development: Theory and Applications: Theory and Application. Thousand Oaks, CA: Sage; 2003.

31. Kimberlin CL, Winterstein AG. Validity and reliability of measurement instruments used in research. Am J Health Syst Pharm. 2008; 65(23):2276-2284.

32. DeVon HA, Block ME, Moyle-Wright P, et al. A psychometric toolbox for testing validity and reliability. J Nurs Scholarsh. 2007;39(2): 155-164.

33. Chen J, Park Y, Putzer GJ. An examination of the components that increase acceptance of smartphones among healthcare professionals electronic. $J$ Health Inf. 2010;5(2):e16.
34. Pena V, Watson AJ, Kvedar JC, Grant RW. Mobile phone technology for children with type 1 and type 2 diabetes. J Diabetes Sci Technol. 2009; 3:1481-1489.

35. Nes AA, van Dulmen S, Eide E, et al. The development and feasibility of a web-based intervention with diaries and situational feed-back via smartphone to support self-management in patients with diabetes type 2 . Diabetes Res Clin Pract. 2012;97:385-393.

36. Dobson KG, Hall P. A pilot study examining patient attitudes and intentions to adopt assistive technologies into type 2 diabetes selfmanagement. J Diabetes Sci Technol. 2015;9(2):309-315.

\section{Publish your work in this journal}

Patient Preference and Adherence is an international, peer-reviewed, open access journal that focuses on the growing importance of patient preference and adherence throughout the therapeutic continuum. Patient satisfaction, acceptability, quality of life, compliance, persistence and their role in developing new therapeutic modalities and compounds to optimize clinical outcomes for existing disease states are major areas of interest for the journal. This journal has been accepted for indexing on PubMed Central. The manuscript management system is completely online and includes a very quick and fair peer-review system, which is all easy to use. Visit http://www. dovepress.com/testimonials.php to read real quotes from published authors.

\footnotetext{
Submit your manuscript here: http://www.dovepress.com/patient-preference-and-adherence-journal
} 